\title{
Monitoring of the stress-strain state of the surface layer of a part in the cutting process using vibroacoustic diagnostics
}

\author{
Dmitry Allenov, ${ }^{1, *}$, Mikhail Kozochkin², and Irina Andryushchenko ${ }^{1}$ \\ ${ }^{1}$ Russian University of friendship of people, 117198, Miklukho-Maklaya 6, Moscow, Russia \\ ${ }^{2}$ Moscow State University of Technology “STANKIN”, 127055, Vadkovsky per. 1, Moscow, Russia
}

\begin{abstract}
The state of the surface layer after mechanical process influences on the performance characteristics of the parts: corrosion and fatigue resistance, dimensional stability during the operating time. The wear of tools can have a decisive influence on the surface deformation. The present paper is devoted to monitoring the influence of wear on the surface layer using the analysis of vibration signals.
\end{abstract}

\section{Introduction}

Currently in engineering, many parts have to work in conditions of high temperatures, in contact with corrosive media, in the presence of high static and dynamic stresses. All these factors lead to the appearance of various defects on the part surface. Most often, the appearance of such defects occurs in a thin, near-surface layer of parts, which is largely formed when the appropriate processing technology is realized. Practice established a close relationship between the properties of the surface layer of parts and their performance properties, including strength and durability. There are many reasons for this connection [10]. In stressed parts, the surface layer is exposed to more severe conditions; risks and irregularities on the surface are places of formation and development of fatigue cracks; the presence of dislocations and microcracks of an atomic scale at high degrees of deformation promotes the formation of untreated microcracks prone to spreading; when parts are used in conditions of high temperatures, strength-free parts without deformation hardening prevail; large degrees of deformation reduce the parts resistance to corrosionmechanical failure and reduce the resistance of protective coatings, and also affect the relaxation rate of the surface layer properties and its weakening.

Since the set of properties of the processed surface characterize the quality of the surface layer of the processed part, or the quality of the treatment, many researchers all around the world have studied the effects of cutting regimes and the geometry of the cutting tool on these properties. It was found that the properties of the surface layer begin to form in the zone of advanced hardening before the cutting edge of the tool. The development of a dislocation structure in the form of slip bands, an increase in the dislocation density lead to hardening of the surface layer $[3,10,13,14]$. The intensity of hardening of the surface layer, determined by the density of dislocations, depends on the level of the applied load and the action time. In turn, the dislocation density is closely related to the increase in the hardness of the hardened material and the degree of its hardening. In the literature, it is noted that with increasing hardening of the treated surface, the heterogeneity of the properties of the surface layer also increases, even if all processing conditions are constant. The heterogeneity of the surface layer is manifested in the nonuniform distribution of point defects, surface areas are characterized by different chemical properties. A micro relief is formed on the surface with irregularly shaped dimples and projections, with a random distribution of height and pitch of microroughness. This leads to the appearance in the surface layer of places with increased tendency to cracking, corrosion, adhesion and abrasion [13]. In the process of chip separation, the thickness of the layer jammed by the cutting edge changes randomly, creating the prerequisites for the nonuniform hardening of the surface layer and the fluctuation of the microroughness parameters.

A latent energy of deformation accumulated by the surface layer as a result of hardening can serve as an integral characteristic of the stress-strain state $[2,13]$. This energy is accumulated as a result of elastic distortions of the crystal lattice caused by an increase in the dislocation density. The lower the latent energy of deformation in the surface layer creates the higher fatigue resistance of a part operating at ordinary temperature. When working in conditions of elevated temperatures, this effect is particularly pronounced.

An important consequence of the instability of the physical-mechanical state of the surface layer after cutting is the violation of dimensional stability of parts after some time after treatment. This problem is relevant not only for thin-walled products, but also for precise details.

An experimental assessment of the influence of technological parameters on the accumulation of hidden

\footnotetext{
"Corresponding author: allenov dg@,rudn.university
} 
surface energy has shown that there is an ambiguous effect of the same parameters on the level of latent energy when processing various materials. It has been experimentally established that the wear of the cutting edge of tools affects the accumulation of the latent energy of deformation at times to a greater extent than the cutting regimes [13]. The effect of tool wear on the level of hidden energy is further complicated by the fact that there is no identical evaluation of the very nature of wear. The adopted wear control on the back face does not guarantee its fair evaluation with respect to the influence on the accumulation of the hidden energy of deformation of the surface layer of the part. It is shown in [9] that wear forms occur when the tool with a greater faceted wear on the back side creates less surface deformations than a tool with less wear and tear on the back side. It suggests that widespread periodic monitoring of radial wear can not guarantee the stability of the surface layer of the part, since radial wear can be recalculated into wear at the back edge, but the uncertainty of the force impact on the surface of the part will remain large due to the accidental nature of the fractures. The rounding radius of the cutting edge has only a statistical connection with the wear facet at the back edge. In addition, modeling the destruction of the cutting edge in the form of a portion of a cylindrical surface is often a very remote approximation to the real form [4]. The purpose of this research is to create an integrated system for ensuring the quality of the surface layer during blade processing by controlling indirect parameters.

\section{Monitoring of the tool wear state}

It is known that the destruction of the cutting edge, which causes intensive deformations of the treated surface, leads to an increase in the energy consumed, corresponding to an increase in cutting forces and the amount of heat released. The control of cutting forces can be carried out by changing the active power consumed by the drives on the machine. However, in the final treatment regimes, the method does not always give satisfactory accuracy. This is especially noticeable for finishing with a large ratio of the engine power used and the power used for cutting [7]. This situation is typical for processing centers, where both roughing and finishing of parts from different materials and different configurations are carried out. Temperature control in the cutting zone is a difficult task even for laboratory conditions. The connection between the vibroacoustic (VA) activity of the cutting process and wear of the cutting tool is widely noted in the technical literature. VA signals are relatively easy to control with the help of accelerometers, but the disadvantages of VA diagnostic methods include the difficulty of isolating useful information from the set of parameters of VA signals accompanying cutting. The most simple parameters of VA signals, which are easily obtained in digital or analog form, are the effective amplitudes in the allocated frequency bands. That is, the distortion of the shape of the VA signal spectrum can be used as a diagnostic indication of the change in the state of the cutting tool. Distortion of the shape of the spectrum assumes a change in the ratio of effective amplitudes for different frequency ranges. The increase in heat release in the area of contact between the surfaces of the tool and the material being processed leads to a change in the mechanical properties in the friction pair, for example, to a decrease in the hardness of the material being processed. It was shown in $[6,8]$ that the amplitude of the high-frequency VA signal in the frictional contact in the first approximation with increasing hardness of the softer element of the friction pair increases linearly. Thus, with increasing temperature (and a drop in the mechanical characteristics of the material being processed) in frictional contact under conditions of adhesive friction, the high-frequency components in the spectrum of the VA signal should decrease. On the other hand, the growth of the load in the contact tool with the machined surface causes additional deformation of the entire technological system and increases its potential energy [5], making it less stable when chip elements are allocated. The situation can be aggravated by a decrease in the bearing capacity of the cutting surface with an excessive increase in the contact temperature, which forms a ripple of the surface and instability of the properties of the surface layer. When separating the chips, the balance of forces in the process system is violated, leading to the emergence of potential energy, the relaxation of elastic deformations with the appearance of oscillations at the natural frequencies of the technological system. According to the above, it follows that with an increase in the potential energy determined by the cutting forces, the oscillations in the technological system in the region of comparatively low frequencies will also grow. This allowed us to use the ratio of the effective amplitudes (Kf) of the vibration signal in the region of high and low frequencies as a diagnostic feature. Fig. 1 shows examples of the spectra of VA signals from the accelerometer that accompanied the turning of a roller of steel 45 with a depth of $0.5 \mathrm{~mm}$, a feed of $0.15 \mathrm{~mm} / \mathrm{rev}$, with a cutting speed of $47 \mathrm{~m} /$ min. The spectra are presented to illustrate extreme situations in the experiment: for cutting an acute plate and a plate that caused the greatest deformation of the surface layer. On the inset in the corner of Fig. 1 shows the change in the diagnostic parameter $\mathrm{K}_{\mathrm{f}}$ for five plates with different wear of the cutting edge, the number of which increased with increasing influence on the strain rate of the surface layer.

Fig. 1 shows clearly that when the worn-out No. 5 plate was used, the amplitudes in the low-frequency region $(0.7-1.5 \mathrm{kHz})$ increased in the BA signal spectrum, but in the high-frequency region $(4-15 \mathrm{kHz})$ there was a significant decrease in amplitudes 


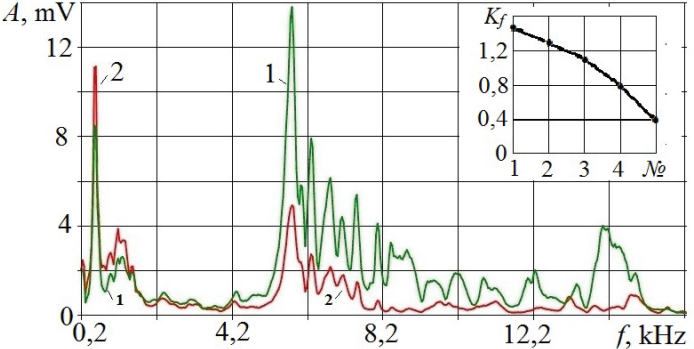

Fig. 1. Spectra of VA signals for sharp (spectrum 1) and blunt (spectrum 2) plates, on the inset change in the values of the parameter Kf with increasing wear influence on the deformation of the surface layer (plate numbers are given).

If we take the ratio $\mathrm{Kf}$ of the effective amplitudes for the indicated high-frequency and low-frequency ranges, then when working with an sharp plate $\mathrm{Kf}=1.5$, and when working with plate No. 5 , the ratio $\mathrm{Kf}=0.4$. The inset in Fig. 1 shows the graph of the change in Kf with the increase in the number of all the cutting inserts used in the experiments. The values of $\mathrm{Kf}$ decrease monotonically in accordance with the increase in the intensity of surface deformations caused by the degradation of the cutting edge. At the same time, wear was formally measured according to the width "h" of the chamfer of wear along the rear face: $1-\mathrm{h} 1=0 \mathrm{~mm} ; 2$ $\mathrm{h} 2=0.6 \mathrm{~mm} ; 3-\mathrm{h} 3=0.68 \mathrm{~mm} ; 4-\mathrm{h} 4=1.1 \mathrm{~mm} ; 5-\mathrm{h} 5$ $=0.8 \mathrm{~mm}$. It can be seen that the largest chamfer of wear along the back face was at sample No. 4, and the smallest value of $\mathrm{Kf}$ was at plate number 5 . This is explained by the fact that on the wear face there were random stains, which determined deformations of the treated surface.

\section{Monitoring of the stress-strain state}

Measurements of the deformations of surfaces treated with the five plates presented made it possible to construct the dependence of the parameter $\mathrm{Kf}$ on the intensity of deformation of the surface of the parts cint. To measure the intensity of deformations, we used the experimental method of fission grids applied to the side surfaces of a billet with a mesh size of $50 \mu \mathrm{m}$ [16]. In Fig. 2 is a graph of this relationship. On the chart, it is possible to single out sections of run-in, normal wear and catastrophic wear.

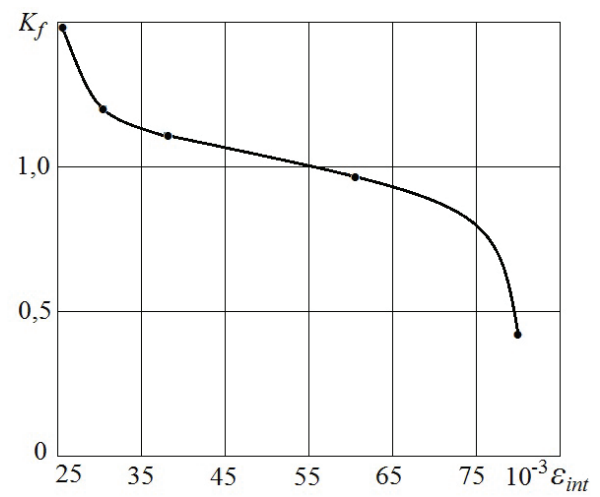

Fig. 2. The parameter change of Kf with increasing strain intensity of sint of the Surface layer.
Kf parameter can be used to monitor of tool wear effect on the intensity of deformation of the surface layer, but with constant processing modes.

When changing the processing modes, Kf values may vary, causing a change in the criteria for the failure of the tool.

Diagnostic parameter search, which was sensitive to a change in the instrument state, but varied little with the processing modes changes, is also a significant goal of ongoing research.

Practice has shown that the VA signals and $\mathrm{Kf}$ parameter depend on the cutting speed to the greatest extent.

Fig. 3 shows the dependence of $\mathrm{Kf}$ on the cutting speed for an acute and worn tool when sharpening an alloy NiCr20TiAl.

Being a tool with wear values, $\mathrm{Kf}$ change five times when changing the cutting speed from 15 to $50 \mathrm{~m} / \mathrm{min}$.

Fig. 3 shows the change graph of qf, defined as the value relation of $\mathrm{Kf}$ with an acute tool to the value of $\mathrm{Kf}$ with a blunted instrument.

It is obvious that the cutting speed of qf varies within $20 \%$ in the entire range, with real speed variations relative to the optimum value for the alloy NiCr20TiAl, qf changes are no more than $5 \%$.

Thus, knowing $\mathrm{Kf}$ values for different cutting regimes for an acute tool, it is possible to monitor $\mathrm{qf}$ value in a wide range of variation of the cutting conditions, with a single failure criterion to have [qf].

For the case shown in Fig. 3 the failure criterion [qf] $=2$, which means $\mathrm{Kf}$ decrease is allowed from the initial level of 2 times.

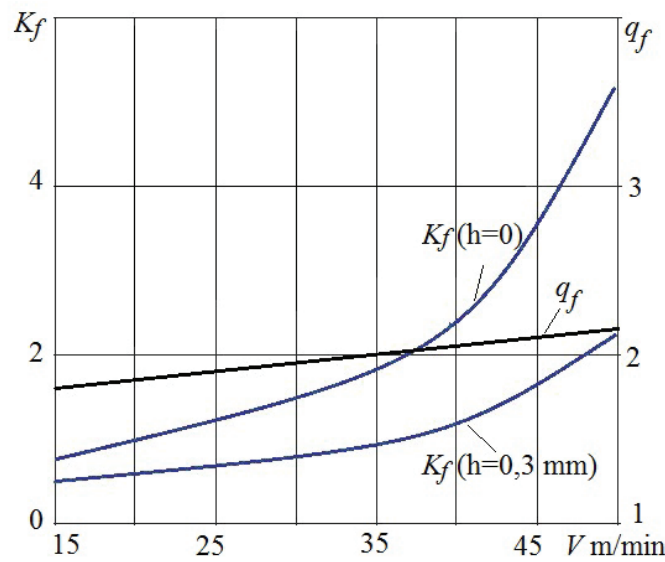

Fig. 3. Variation in $\mathrm{Kf}$ and $\mathrm{qf}$ values for the cutting speed variation during the sharpening the alloy NiCr20TiAl.

It is important to note that intense self-oscillations may occur in the process of cutting with the processing conditions change, under which $\mathrm{Kf}$ behavior may be violated.

At high requirements of surface quality, work with self-oscillations should be eliminated.

The detection of modes with self-oscillations can be done using the VA signals analysis [8]. 


\section{Conclusion}

There is a close connection between the latent surface energy, the dislocation density and the number of microcracks with the deformation intensity of the surface layer during the blade machining of the parts.

For parts with high requirements for dimensional, corrosion and fatigue stability, it is necessary to monitor the instrument state changes affecting the deformation of the surface layer of machined parts in automated production environments.

It was shown that this function could be executed by the VA signals analysis accompanying cutting.

As a diagnostic parameter, good prospects for use were established at the ratio of the effective amplitudes of the VA signals taken in the high-frequency and lowfrequency ranges, which reflect the shape distortion of this signal spectrum

Further VA monitoring can be obtained for monitoring operations related to nano- cutting [15], where the state of the surface layer plays a decisive role.

\section{References}

1. A. Samraj, S. Sayeed, J. Emerson Raja, J. Hossen, A. Rahman, Dynamic clustering estimation of tool flank wear in turning process using SVD models of the emitted sound signals, World Academy of Science, Engineering and Technology 80, pp. 13221326 (2011)

2. V.F. Bezjazychnyj, B.M. Drapkin, M.A. Prokofiev, M.V. Timofeev, Research of stored energy of deformation by metal during indentation by sphere indenter [Issledovanie zapasennoi metallom energii deformatsii pri vdavlianii charovogo indentora], Zavodskaya labortoriya. Diagnostika materialov [Factory laboratory. Material diagnostics], no.4, t.71, pp.32-35 (2005)

3. V.F. Bezjazychnyj, M.A. Prokofiev, A.N. Sutyagin, Technological Assurance of Wear Resistance of Surface Layer of Machine Parts After Turning, Russian Internet Journal of Industrial Engineering, Vol. 2, no. 4, pp. 42-46. (2014) (http://industengineering.ru/)

4. I.R. Dobrovinskiy, Yu.T. Medvedik., M.Yu. Medvedik, V.S. Chapaev, Povolzhskiy region. Tekhnicheskie nauki, Izvestiya vysshikh uchebnykh zavedeniy. [University proceedings. Volga region. Engineering sciences], no. 2 (26), pp. 59-70 (2013)

5. M.P. Kozochkin, Influence of Machine_Tool Dynamics on the Vibration in Cutting. Russian Engineering Research, Vol. 34, No. 9, pp. 573-577 (2014)

6. M.P. Kozochkin, Nonlinear cutting dynamics. Russian Engineering Research, 32 (4), (2012 (13)

7. M.P. Kozochkin, A.R. Maslov, and A.N. Porvatov, Information-measurement and control systems for force and vibroacoustic parameters, Measurement Techniques, Vol. 58, No. 8, pp. 839-844 (2015)
8. M.P. Kozochkin, A.N. Porvatov, Effect of Adhesion Bonds in Friction Contact on Vibroacoustic Signal and Autooscillations, Journal of Friction and Wear, Vol. 35, No. 5, pp. 389-395 (2014)

9. M.P. Kozochkin, M.A. Volosova, D.G. Allenov Effect of wear of tool cutting edge on detail surface layer deformation and parameters of vibro-acoustic signals, Materials Science Forum, Vol. 876, pp 5058 (2016)

10. V.S. Muhin, Poverhnost: tehnologicheskie aspekty prochnosty detaley GTD. (Moscow: Nauka, 2005)

11. S. Orhan, A. Osman, Er, N. Camus-cu, E. Aslan, Tool wear evaluation by vibration analysis during end milling of AISI D3 cold work tool steel with 35 HRC hardness, NDT\&E International 40, pp. 121126 (2007)

12. A.S. Sidorov, Monitoring i prognozirovanie iznosa rezhushchego instrumenta $v$ mekhatronnykh stanochnykh sistemakh [Monitoring and forecasting tool wear in mechatronic machine systems], Abstract of dissertation for the degree of Candidate of Technical Sciences (Ufa, 2007)

13. V.K. Starkov, Dislokatsionnye predstavleniya o rezanii metallov [Dislocation representations about metal cutting] (Mashinostroenie, Moscow, 1979)

14. A.G. Suslov, Technologicheskoe obespechenie parametrov sostoyaniya poverchnostnogo sloya [Technological assurance of surface layer quality parameters] (Mashinostroenie, Moscow, 1987)

15. Q. Wang, Q. Bai, J. Chen, Y. Sun, Y. Guo, Y. Liang, Subsurface defects structural evolution in nano-cutting of single crystal copper, Appl, Surf Sci.; 344, pp. 38-46 (2015)

16. Werkstüchklassifizierung und auswahl für ein flexibles//Fertigungssystem Madrich. Oberkochen H. «Werkstatts technik». 71. №8. P. 485-489 (1981) 